\title{
RECENT ADVANCES IN THE UNDERSTANDING OF HOMOGENEOUS DIELECTRIC BARRIER DISCHARGES
}

\author{
Massines F. ${ }^{a^{*}}$, Gherardi N. ${ }^{\text {b,c }}$, Naudé N., ${ }^{\text {b,c }}$, Ségur P. ${ }^{b, c}$ \\ a) CNRS-PROMES, Tecnosud, Rambla de la thermodynamique, 66100 Perpignan, France \\ b)Université de Toulouse; UPS, INPT; LAPLACE (Laboratoire Plasma et Conversion d'Energie); 118 route de \\ Narbonne, F-31062 Toulouse cedex 9, Franc. c)CNRS; LAPLACE; F-31062 Toulouse, France.
}

\begin{abstract}
This paper is a state of the art of the understanding on the physics of homogeneous dielectric barrier discharge at atmospheric pressure. It is based on the analysis of present and previous work about the behavior of these discharges and the conditions to get them. Mechanisms controlling the homogeneity during gas breakdown and discharge development are successively discussed. The breakdown has to be a Townsend one, the ionization has to be slow enough to avoid a large avalanche development. During the breakdown, the discharge homogeneity is related to the ratio of the secondary emission at the cathode ( $\gamma$ coefficient) on the ionization in the gas bulk ( $\alpha$ coefficient). Higher is this ratio, higher is the pressure $\times$ gas gap product (P.d.) value for which a Townsend breakdown is obtained. Among the phenomena enhancing the secondary emission there is the negative charge of the dielectric on the cathode surface, the trapping of ions in the gas and the existence of excited state having a long lifetime compared to the time between two consecutive discharges. The first phenomenon is always present when the electrodes are covered by a solid dielectric, the second one is related to the formation of a positive column and the third one is specific of the gas. During the discharge development, the homogeneity is mainly controlled by the voltage or the current imposed by the electrical circuit lelectrode configuration and to the gas ability to be slowly ionized. Larger is the contribution of a multiple step ionization process like Penning ionization, higher will be the working domain of the discharge. A decrease of the gas voltage during the discharge development is a solution to enhance the contribution of this process. After 20 years of research a lot of mechanisms have been understood however there is still open questions like the nature of the Inhibited homogeneous DBD, surface energy transfers, role of attachment and detachment...
\end{abstract}

\section{INTRODUCTION}

Dielectric barrier discharge (DBD) is an easy and robust solution to generate low temperature discharge at atmospheric pressure [1]. This discharge has a lot of applications since more than one century [2]. Its configuration uses dielectric barriers to maintain current densities below the threshold for glow-to-arc transition. The dielectrics trap charges on the surfaces during a pulse which in turn generate a self-induced field in the gas gap that inhibits the discharge before the current density exceed the threshold.

It was long thought that for gas gap in the millimetric range or larger, DBD only occurs in a "filamentary" mode, comprising many short $(<100 \mathrm{~ns})$, narrow $(<200 \mu \mathrm{m})$ current filaments, in general randomly distributed in time and space over the dielectric surface. Even if several authors $[3,4]$ reported that ac discharges in helium can also manifest a pulseless "glow", in which the atmospheric-pressure discharge assumes a diffuse, non-filamentary appearance, it is the work of Okazaki and their collaborators since 1987 [5] which has been at the origin of a real investigation of homogeneous DBD. Okazaki, Kogoma et al. studied a lot of different reactor configurations $[5,6,7,8]$ to extend the gases panel leading to homogeneous DBD which at first was limited to helium. They also have shown the interest of these discharges for gas and surface chemistry. In parallel, since 1992 in France, Massines, Ségur and their collaborators [9] have focused on the understanding of these discharges physics mainly in $\mathrm{He}[10,11,12]$ and $\mathrm{N}_{2}[13,14,15]$ and their application to polymer surface treatments $[16,17]$ and thin film coatings $[18,19,20]$. At the same time in United States, Roth and collaborators have worked on all the possible applications $[21,22,23,24]$ including sterilisation $[25,26]$ and gas flow control $[27,28]$.

These three teams generated a confusing list of names for homogeneous DBD: Okazaki and Kogoma

*Electronic address: francoise.massines@univ-perp.fr 
always used Atmospheric Pressure Glow Discharge (APGD) because in He, the gas they studied at first, the glow of the homogeneous DBD is significantly larger than that of a filamentary DBD. Roth chose One Atmosphere Uniform Glow Discharge Plasma (OAUGDP) to be more descriptive and Massines suggested that the name of these pulsed discharges should give an indication about the highest ionisation level they can reach (as detailed later) defining Glow DBD (GDBD or APGD) and Townsend DBD (TDBD or APTD).

When the scientific community has been convinced of the homogeneous DBD robustness, more and more teams, often driven by applications, have begun to work on these discharges. Consequently, over the last decade, these discharges have been intensively studied, finding new configurations which help the discharge stabilisation [29,30,31], increasing our knowledge on the discharge physics and chemistry $[32,33,34,35,36,37,38,39,40,41,42,43,44,45,46]$, and showing the advantage of high (atmospheric) pressure operation with (i) high degree of discharge uniformity over $\mathrm{cm}$ length scales and (ii) thermal and chemical non-equilibrium. Numerous new applications including thin film deposition $\quad[18, \quad 19,20,21,47,48,49,50,51,52,53,54,55,56,57,58,59], \quad$ bio-decontamination $[26,60,61,62,63,64,65]$, and aerodynamic flow control $[28,66,67,68]$ have been demonstrated.

The creativity in the field of homogeneous DBD is large and as the aim of this paper is the understanding of these complex discharges and not their applications, we will mainly focus on the simplest configuration: 2 plane parallel electrodes, a low frequency excitation allowing only one breakdown each half cycle and a gas gap large enough to get filamentary discharges. The gas gap, $\mathrm{d}$, is important because it is not only the pressure, P, but the product (P.d) which determines the ionisation mechanisms: the ratio of electron emission at the cathode over the ionisation in the gas bulk is determined by the ratio of the electron mean free path over the gas gap. More precisely, for low p.d product value, typically lower than 30 Torr.cm, the breakdown is a Townsend breakdown defined by the $\gamma$ emission of electron at the cathode and the gas bulk ionisation defined by the effective ionisation coefficient $(\alpha)$. The time scale of this breakdown is in the range of $\mu$ s and the discharge area is equal to that of the electrodes. For high p.d values (p.d $>200$ Torr.cm) breakdown is a streamer one due to the formation of one electronic avalanche large enough to create a sufficient amount of ions $\left(\sim 10^{8}\right)$ to get a space charge field of the order of magnitude of the applied field. If this condition is fulfilled, breakdown can occur without a significant contribution of the cathode surface and the transition from Townsend to streamer breakdown occurs: the positive space charge induces a localization of the electric field which accelerates the electrons created between the cathode and the positive space charge by photo-ionisation or photo-emission. The time scale of this breakdown mechanism is in the range of nanoseconds and in a DBD, when the streamer has connected the two electrodes, a micro-discharge having a radius of typically one or two hundred of $\mu \mathrm{m}$ develops.

DBD can be separated in two groups: those due to a streamer breakdown and those due to a Townsend breakdown. The first one usually leads to a filamentary discharge while the second one leads to a homogeneous discharge. However, the connection between the breakdown mechanism and the discharge homogeneity is not fully satisfied: when the density of seed electrons increases, the density of large size avalanches also increases, inducing avalanches interactions, streamer coupling and more or less homogeneous discharges. This needs a preionisation process like photo-ionisation, and these discharges are only stable under nanosecond excitation which ensures the simultaneous development of the first avalanches. Thus we will not discuss these specific discharges.

Before going into the physics of the discharge, we have to define the homogeneous DBD. Most of the times, the different studies are driven by teams previously working on atmospheric pressure thermal plasmas or on low-pressure non-equilibrium plasmas that have converged in the field of nonequilibrium atmospheric pressure discharges. Under the influence of Okazaki's work, they usually consider that a glow discharge is an homogeneous discharge but they defined the glow discharge according to their own experience: for those who come from the thermal plasmas, an atmospheric pressure glow discharge is a discharge not so conductive as an arc i.e. characterised by a relatively low current under high voltage; for those having a low-pressure plasma background, a glow discharge means a high current under low voltage discharge having a specific structure from the cathode to the anode including cathode fall, Faraday dark space and positive column. Thus, the approach to try to get the APGD will be different in the two cases: the first ones will try to limit the current, the second ones 
to get a Townsend breakdown similar to low-pressure plasma. However, for all of us a homogeneous DBD is free of streamer and micro-discharge.

At the end, the two approaches are necessary to get a stable homogeneous DBD. The mechanisms leading to a reliable homogenous DBD can be separated in those controlling the breakdown and those controlling the discharge development. The first condition is to get a Townsend breakdown, the second one to limit the discharge development in order to avoid an ionisation level that would be too high. To fulfill the first condition, the " $\gamma$ emission" has to be enhanced compared to the " $\alpha$ ionization". As for the second condition, the rise and the amplitude of the current have to be limited i.e. the power supply and the electrode configuration has to be designed to slow down the ionisation. Before detailing our understanding of these issues, we will discuss the different homogeneous DBD regimes and highlight the memory effect from one discharge to the next and the consequence it has on the breakdown conditions.

\section{THE DIFFERENT HOMOGENEOUS DBD}
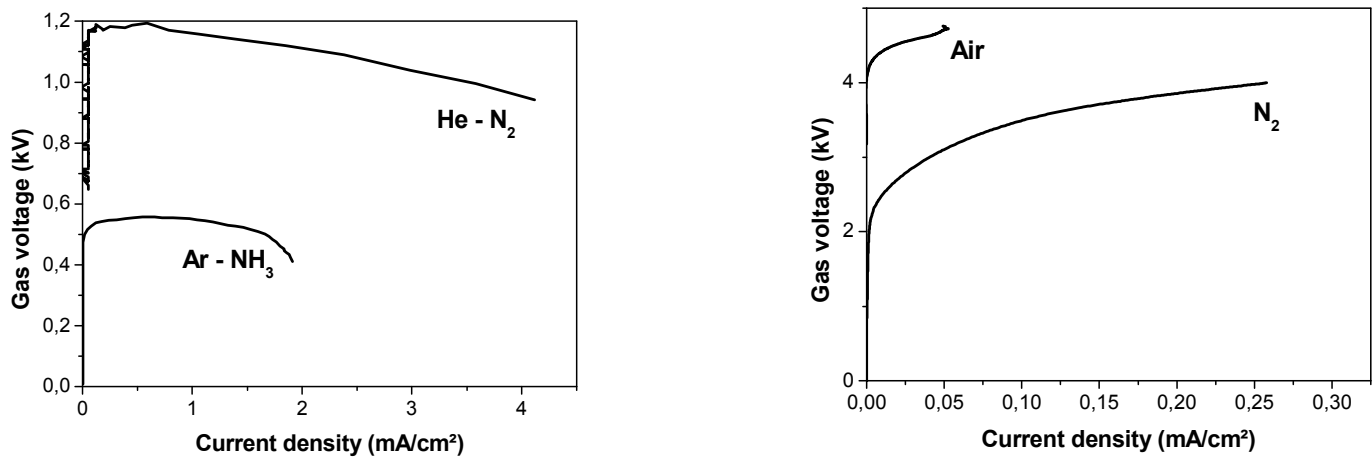

FIGURE 1. Gas voltage as a function of the current density during the current increase for He APGD; $\mathrm{Ar}_{-} \mathrm{NH}_{3}$ APGD ; $\mathrm{N}_{2}$ APTD ; air APTD

\begin{tabular}{|c|c|c|}
\hline & APTD - TDBD & APGD - GDBD \\
\hline Electron density maximum $\left(\mathrm{cm}^{-3}\right)$ & $10^{7}-10^{8}$ & $10^{10}-10^{11}$ \\
\hline Ions density maximum $\left(\mathrm{cm}^{-3}\right)$ & $10^{10}$ & $10^{11}$ \\
\hline Neutral plasma formation $\left(\mathrm{n}_{+}=\mathrm{n}_{-}\right)$ & No & Yes (positive column) \\
\hline Metastable of the dilution gas & $10^{13}$ & $10^{11}$ \\
\hline Current density $\left(\mathrm{mA} / \mathrm{cm}^{2}\right)$ & 0.1 to 10 & 10 to 100 \\
\hline $\begin{array}{l}\text { Gas voltage variation around the } \\
\text { current maximum }\end{array}$ & Constant (Townsend plateau) & Decrease (cathode fall formation) \\
\hline Dilution gases & $\mathrm{N}_{2}$, Air, $\mathrm{N}_{2} \mathrm{O}$ & Penning mixture in $\mathrm{He}, \mathrm{Ar}, \mathrm{Ne}$ \\
\hline Typical gas gap & $<2 \mathrm{~mm}$ & $>2 \mathrm{~mm}$ \\
\hline Typical frequency range & $<10 \mathrm{kHz}$ & $>1 \mathrm{kHz}$ \\
\hline Power for a $10 \mathrm{kHz}$ excitation & Some $\mathrm{W} / \mathrm{cm}^{3}$ & Some $0.1 \mathrm{~W} / \mathrm{cm}^{3}$ \\
\hline Solutions to observe micro-discharge & Current (Cf Fig.3), optical method & Photomultiplier, ICCD \\
\hline
\end{tabular}

TABLE 1. Order of magnitude of the different species in the two well characterized homogeneous DBD regimes

To be out of equilibrium, the DBD is an inherently pulsed discharge and each discharge can be considered as a direct current discharge only related to the others by the memory effect from one discharge to the following one. The discharge regime is then determined by the maximum ionisation rate reached by each discharge. Figure 1 compares different voltage-current characteristics obtained during the current increase of one discharge pulse in different gases. Conditions leading to these discharges are described in [5] for $\mathrm{He},[69,70]$ for $\mathrm{Ar}-\mathrm{NH}_{3}$, [13] for $\mathrm{N}_{2}$ and [8,71] for air.

Before breakdown, the current is related to the memory effect which can be considered as an external source of electrons. During the current increase induced by the gas breakdown, first the voltage continues to increase, and then it stabilizes to the Townsend plateau value. If a positive column is 
formed, the voltage decreases while the current continues to increase [72]. This is the case for He and $\mathrm{Ar}+\mathrm{NH}_{3}$ but not in $\mathrm{N}_{2}$ and air. Thus the homogeneous discharge in $\mathrm{He}$ and $\mathrm{Ar}+\mathrm{NH}_{3}$ are usually APGD but the homogeneous DBD in $\mathrm{N}_{2}$ and air are not usually APGD. The discharge stops before reaching the ionisation level necessary to localize the cathode fall. As the voltage reaches the Townsend plateau value, the homogeneous discharge in $\mathrm{N}_{2}$ or in air has been considered as a Townsend DBD or APTD. Differences between APTD and APGD are summarized in table 1. One of them is that the APGD is a discharge which does not generate an electrically neutral ionized gas like a positive column. In the APTD the maximum electron density is 3 orders of magnitude lower and the mean power dissipated is typically one order of magnitude larger than in the APGD. Indeed, in a pulsed discharge, the power is determined by the maximum energy but also by the pulse duration: when the current is lower the pulse duration is usually longer and the power does not significantly change.

Another family of homogeneous discharge has been obtained adding specific component to the set-up like a resistive layer on the electrode [29] or a choke coil in series with the discharge working in the saturation regime [31]. The choke coil prevents the fast current increases and the resistive material induces a local decrease of the gas voltage proportional to the local current. Up to our knowledge, there is no information available about the physics of these discharge and the densities of their main species. To reach a better understanding, a fluid model of a He- $\mathrm{N}_{2}$ APGD has been developed and the influence of a resistor in series with the electrodes has been studied. As shown in Figure 2, as the resistance value increases, the ion density decreases, the positive column disappears. However, due to the resistor the electrical field decreases when the current increases, then even if there is no positive column, the discharge is not a Townsend discharge (which should be obtained under a higher voltage than the glow one). It is a discharge mainly controlled by different ionization processes as proved by the larger contribution of $\mathrm{N}_{2}^{+}$compared to $\mathrm{He}^{+}$or $\mathrm{He}_{2}{ }^{+}$. The decrease of the voltage enhances the contribution of ionization process occurring under low field compared to those needing a larger field. This discharge is neither an APTD nor a real APGD, at this stage we propose Inhibited APGD.

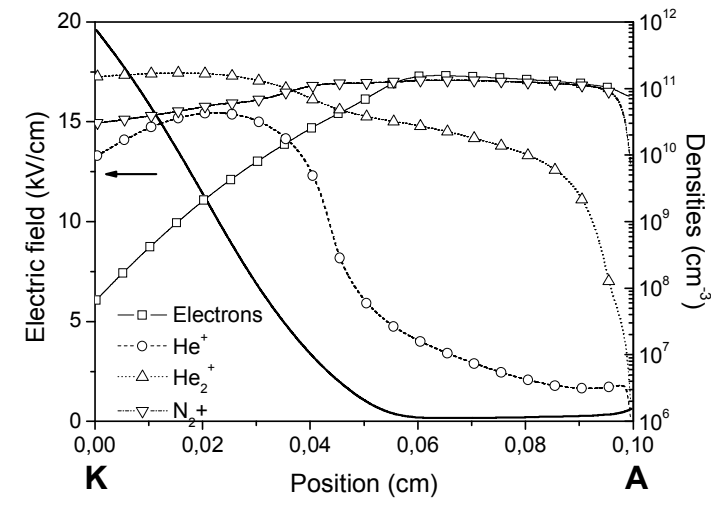

a) $\mathrm{R}=0 \mathrm{k} \Omega$

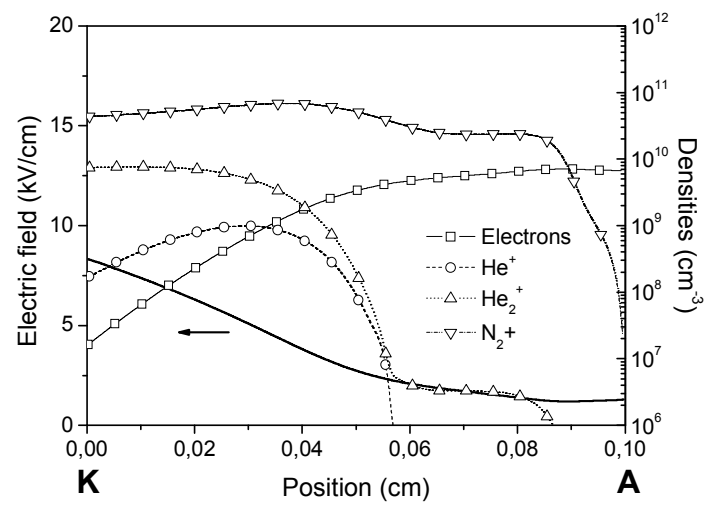

b) $\mathrm{R}=100 \mathrm{k} \Omega$

FIGURE 2. Influence of a resistor in series with a He- $\mathrm{N}_{2}$ APGD: Electric field, electrons and ions distribution from the anode to the cathode when the current is maximum, for $\mathrm{R}=0$ and $\mathrm{R}=100 \mathrm{k} \Omega$ (fluid model results)

Another approach to get a homogeneous DBD consists in inserting a metallic mesh between the dielectric and the electrode $[8,32,73,74,75,71]$. Lindmayer et al. suspected an influence of partial discharges occurring around the mesh [73,74]. Trunec et al. thought about a resistive behavior of the metallic mesh [32]. Our experience shows that an important point is the epoxy resin which is used to fix the mesh. Indeed, similar results have been obtained without the mesh, by sticking the electrode directly on the dielectric with the resin, which is an insulating material [71]. In that case, the discharge obtained in air has the same behavior as in $\mathrm{N}_{2}$.

In conclusion, the physics of APGD and APTD is now well understood that of inhibited homogeneous DBD are still misunderstood. 


\section{MEMORY EFFECT EVIDENCES}

As illustrated in figure 3, whatever the conditions, the role of the memory effect is pointed out by the evolution of the first discharges after ignition: the first two discharges are different from the following ones showing that one DBD pulse depends on the previous one and that some discharges are necessary to reach the equilibrium.

In the case of the Townsend DBD in $\mathrm{N}_{2}$, there is no doubt about the interpretation of the current measurements: the first discharge is filamentary, the second one is a mix of a Townsend discharge and micro-discharges and the third one is fully a Townsend one. Note that the current of the APTD is low (even for a $10 \mathrm{~cm}^{2}$ electrode) compared to that of a streamer. Therefore, in the APTD case, without any current limitation, the current measurements are sufficient to determine if there are micro-discharges or not (Cf. table 1).

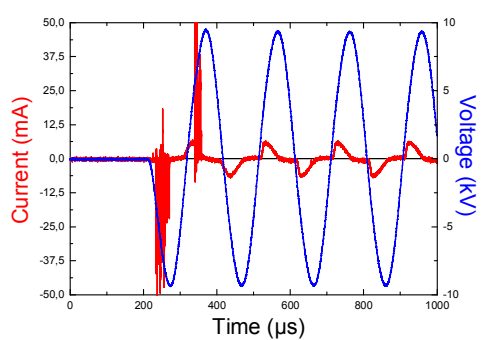

(a)

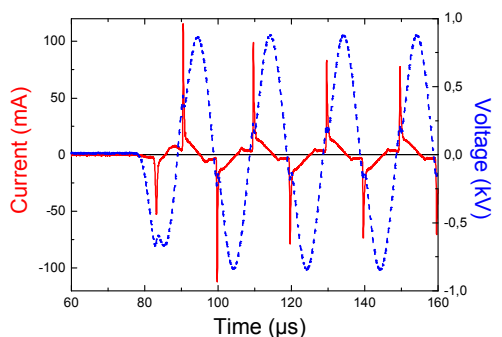

(b)

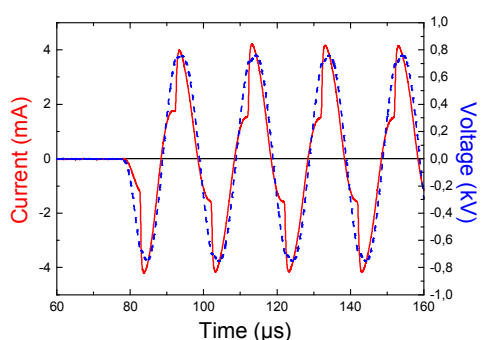

(c)

FIGURE 3. First discharges in (a) $\mathrm{N}_{2}$ APTD, (b) He- $\mathrm{N}_{2}$ APGD (c) He- $\mathrm{N}_{2}$ APGD with a current limitation. $10 \mathrm{~cm}^{2}$ electrode area

In the case of noble gases (figure 3b), homogeneous DBD reaches higher ionisation level and then higher current amplitude which are of the same order of magnitude or even larger than microdischarge ones. Consequently, the analysis of the current measurement is delicate. Nevertheless, to exhibit a reproducible glow current, the discharge needs several half cycles. If a current limitation is added (Figure 3c) no micro-discharge can be observed but there is a clear evolution from the first to the third current peak. Very similar behaviour has been observed [31] in Ar by adding a choke coil in series with the discharge and using specific dielectrics. However, as shown in figure 4, in Argon, a large current pulse is not a proof of the absence of discharge localisation and/or the presence of microdischarges mixed with the APGD $[69,70,76]$.

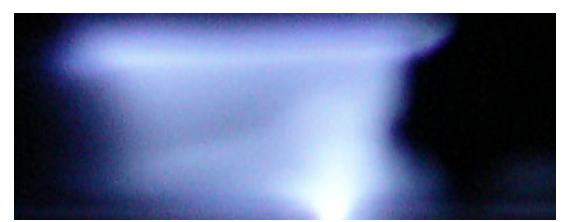

FIGURE 4. Current and voltage oscillograms as well as gas gap picture of a discharge in $\mathrm{Ar}-\mathrm{NH}_{3}$ mixtures. Instabilities are clearly observed on the picture but not on the current oscillogram

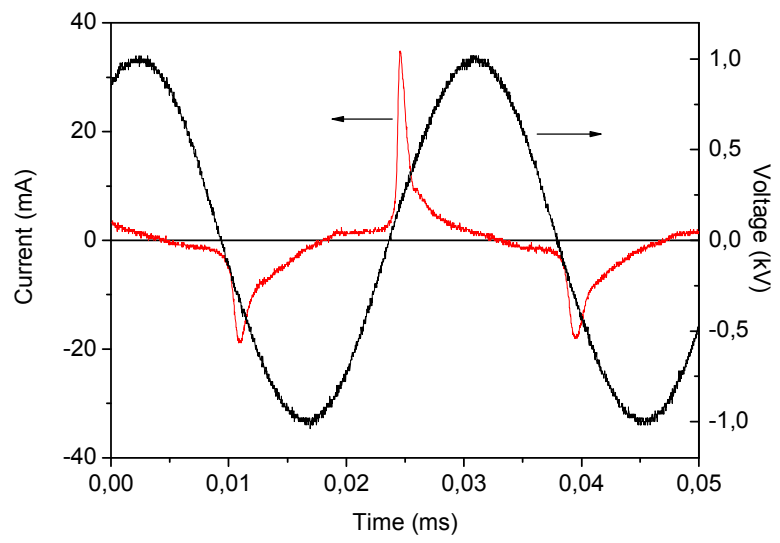

At this stage, the important point is that whatever the discharge regime and the power supply characteristics, there is a clear evolution of the current discharge over the 3 first half cycles and, at least when the current is not limited by the power supply, the memory effect is necessary to get a stable and homogeneous DBD. Note that this evolution is very large compared to that observed at the 10 s or minute time scale $[77,78,79]$ which have been attributed to the variation of the energy stoked in the gas and at the surface [77], to the variation of the secondary emission coefficient of the cathode related to the surface transformations due to discharge interaction [79] or to the temperature increase. 
Memory effect has to be based on species created during one discharge and still present when the next breakdown occurs. Obviously, these species largely influence the breakdown and then the transition between streamer and Townsend breakdown defined by the relative contribution of the surface $\gamma$ emission of electron and the gas bulk $\alpha$ ionisation. After the breakdown, the flux of ions becomes dominant whatever the discharge regime but before the breakdown, energetic species created during the previous discharge and trapped in the gas can play a dominant role allowing a slow ionisation under a too low field to form a large electronic avalanche. In the following part, we will discuss the memory effect mechanisms which are now understood showing how they influence the breakdown and mainly the secondary emission of electrons previous and during the breakdown.

\section{MEMORY EFFECT AND CATHODE SECONDARY ELECTRON EMISSION ENHANCEMENT}

Cathode secondary emission depends on the $\gamma$ secondary emission coefficient of the surface and on the flux of energetic species reaching the cathode surface. These species can be ions, excited states and photons. Emission spectroscopy has shown that photon emission is very low at the first step of the breakdown. Thus, we will focus on "memory" ions and long lived states created during one discharge and still present when the next breakdown occurs. The influence of the memory effect on the secondary emission coefficient of the surface and on the ions and long lived state species will be successively discussed. Then after a synthesis, other mechanisms still under investigations will be presented.

\subsection{Surface charge and secondary emission coefficient}

Knowing the $\gamma$ secondary emission coefficient of a dielectric is not trivial because it depends on the surface charge. In a DBD under alternative excitation, the surface which is on the cathode side during the current increase was on the anode side during the previous discharge: hence it has been charged by an electron flux. These electrons, which are trapped on the dielectric shallow traps, are easier to remove than the intrinsic ones. The deepness of shallow traps is typically $1-2 \mathrm{eV}$ from the void level [80] while the valence band is at $6-8 \mathrm{eV}$. Therefore, this trapping increases the $\gamma$ value at the beginning of the discharge and could explain why the nature of the dielectric does not play a dominant role (except for the first discharges when the memory effect is not yet established [31]) and why a dielectric on each electrode helps to stabilize the discharge [70].

This contribution is proportional to the charge of the solid dielectric. During the current increase, $\gamma$ gradually decreases because of the progressive surface charge neutralization of the cathode. Synchronization between the neutralization of this memory charge of the cathode surface and the current maximum is often observed. A possible explanation is that when $\gamma$ decreases, if $\alpha$ does not increase then the current decreases in good agreement with the reduction of the ionisation. This phenomenon also explains why the voltage necessary to get the same current level is higher during the APTD extinction than during its development (current increase) [70]. If the principle is clear experiments are necessary to be able to quantify these effects of surface charge on the $\gamma$ coefficient and a deeper study of emission mechanism and discharge-surface energy transfers is also necessary.

\subsection{Positive column and "Memory" ions}

Previous studies have shown that it is possible to trap ions from a discharge to the following one [28]. To do so, one needs a neutral plasma zone like the positive column in an APGD and a high enough excitation frequency [11]. The electric field and the ions velocity are low in a positive column. Moreover, due to the ambipolar diffusion, the positive column disappearance in between two discharges is slow and ions can still be present when the next breakdown occurs. This is illustrated in figure 5. According to numerical modelling [11], when the breakdown occurs, the ions density close to the cathode is $10^{9} / \mathrm{cm}^{3}$ and their flux at the cathode is around $8.10^{13} / \mathrm{cm}^{2} . \mathrm{s}$ allowing a significant emission of electrons from the cathode and then the development of a lot of small electronic avalanches under low field and a Townsend breakdown.

Of course ions density decreases with time and such a mechanism is not efficient if the excitation frequency decreases too much (typically $<1 \mathrm{kHz}$ ). In an APTD, there is no positive column and ions 


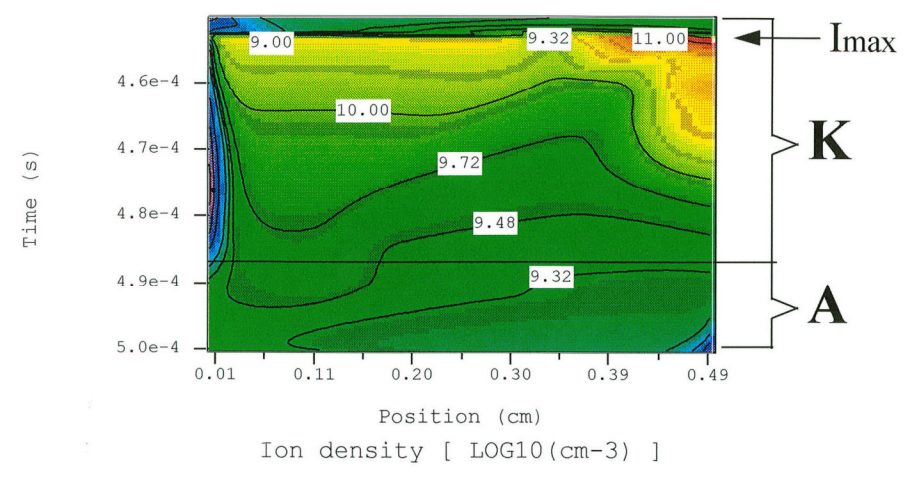

FIGURE 5. Space (anode to cathode) and time (one half cycle) distribution of the ions in aPGD in He calculated with a fluid numerical modelling [81] drift to the cathode at a time scale of $\mu \mathrm{s}$ : they cannot be involved in the memory effect. This is confirmed by the stability of the discharge under low excitation frequency. In conclusion, if a positive column (or neutral plasma) is formed during the discharge development and if the time between two consecutive discharges is not too long, ions created during one discharge induce secondary emission of electrons from the cathode, previous and during the next breakdown.

\subsection{Gas properties and "Memory" long live state species}

The energy required to remove an electron from a shallow trap is about $2 \mathrm{eV}$ which is low in comparison with that of most of the long live state species. Then, these species can actively participate to the cathode secondary emission as far as their flux to the surface is large enough.

The lifetime of noble gases metastables is rather short ( $\mu$ s range) because of the dimmer formation [33]. Consequently in noble gases, the contribution of "memory" long live state species is negligible. However in other gases some metastable states does not react with the gas in its fundamental level and even at atmospheric pressure their life time can be long compareed to the time between two discharges. As example, in $\mathrm{N}_{2}$, measurements of the absolute density of $\mathrm{N}_{2}\left(\mathrm{~A}^{3} \Sigma_{\mathrm{u}}^{+}\right)$metastable have been done by optical-optical double resonance-LIF (OODR-LIF) [82]. Densities as high as $10^{13} / \mathrm{cm}^{3}$ are detected and the experimental quenching rate in $\mathrm{N}_{2}$ is $2.410^{4} / \mathrm{s}$. This long-lived state then represents a reservoir of energy (potential energy of $6.3 \mathrm{eV}$ ) that can be released in numerous reactions producing electrons.

Initially [83] a volume Penning ionisation involving the two metastables $\mathrm{N}_{2}\left(\mathrm{~A}^{3} \Sigma_{\mathrm{u}}{ }^{+}\right)$and $\mathrm{N}_{2}\left(\mathrm{a}^{\mathrm{a}}{ }_{\mathrm{u}}{ }_{\mathrm{u}}{ }^{-}\right)$, and producing $\mathrm{N}_{4}^{+}+\mathrm{e}$, was guessed, but later excluded in the post-discharge on the basis of the too efficient quenching of $\mathrm{N}_{2}\left(\mathrm{a}^{1} \Sigma_{\mathrm{u}}^{-}\right)$in nitrogen [36]. This was verified by adding $\mathrm{Xe}$ to $\mathrm{N}_{2}$ : indeed $\mathrm{Xe}$ efficiently quenches $\mathrm{N}_{2}\left(\mathrm{a}^{1}{ }^{1} \Sigma_{\mathrm{u}}^{-}\right)$but not $\mathrm{N}_{2}\left(\mathrm{~A}^{3} \Sigma_{\mathrm{u}}^{+}\right)$. Thus, if Penning ionisation plays a dominant role, the addition of $\mathrm{Xe}$ in $\mathrm{N}_{2}$ should destabilize the discharge. However, it was observed to have no significant effect on the APTD behaviour. Even if Penning ionisation contributes to the gas ionisation at the first stages of the discharge initiation, this mechanism becomes negligible very quickly after the breakdown because of the rapid variation of the first Townsend coefficient of $\mathrm{N}_{2}$ with the electric field. So the strong structural similarity with a Townsend discharge suggests to bring into play surface effects at the cathode acting as a source of secondary electrons. Spontaneous electron desorption was proposed in [84] leading to a continuous emission of electrons from the cathode. Later, this explanation was excluded because the discharge should work when a $\mathrm{N}_{2}\left(\mathrm{~A}^{3} \Sigma_{\mathrm{u}}{ }^{+}\right)$quencher like $\mathrm{NH}_{3}$ or $\mathrm{O}_{2}$ is added [85]. Then, secondary electron emission by $\mathrm{N}_{2}\left(\mathrm{~A}^{3} \Sigma_{\mathrm{u}}^{+}\right)$impact on the dielectric surface was considered. The discharge being a Townsend discharge, metastables are mainly created near the anode and continuously diffuse to the surface. After the end of the discharge, when the gas voltage polarity reverses, i.e. when the dielectric which was on the anode side becomes on the cathode side, the metastable flux onto the cathode is rather large: $\sim 5.10^{14} / \mathrm{cm}^{2} . \mathrm{s}$ [85]. As metastables induce secondary emission $[86,87]$, this mechanism can continuously produce electrons between two discharges.

\subsection{Synthesis and possible role of electron attachment and detachment}

According to all these results, memory effects allowing to increase the contribution of the secondary emission previous and during the first step of the breakdown can be separated in (i) those always present as soon as the electrode is covered by a dielectric layer which is the surface charge leading to an increase of the $\gamma$ coefficient of the surface, (ii) those related to the formation of a positive column or neutral plasma in which ions can be trapped from one discharge to the following one as far as the 
excitation frequency is high enough, (iii) those depending on the gas properties, namely the existence of an excited state having, at atmospheric pressure, a long lifetime compared to the time between two discharges. These mechanisms explain the electron current observed between two discharges due to the continuous creation of electrons by secondary emission. They ensure a slow breakdown under a low electrical field and hence a Townsend breakdown.

However, the role of memory effect is still not fully understood, as example we are not able to explain why a Townsend breakdown and a Townsend DBD are obtained in pure $\mathrm{N}_{2} \mathrm{O}$. One point that should be emphasised is that, according to numerical modelling, in a case where APTD has been largely studied $\left(\mathrm{N}_{2}\right)$, the three scenarios: Penning ionisation occurring between two discharges [83], spontaneous electron emission [84], and electrons emission induced by $\mathrm{N}_{2}\left(\mathrm{~A}^{3} \Sigma_{\mathrm{u}}{ }^{+}\right)$[85] taken individually reproduce the experimental results observed in $\mathrm{N}_{2}$. Whatever the mechanism, this tends to show that the key point in obtaining a homogeneous discharge is the generation of electrons between two discharges. The role of $\mathrm{N}_{2}\left(\mathrm{~A}^{3} \Sigma_{\mathrm{u}}^{+}\right)$is confirmed by showing that a small adding of quenchers like $\mathrm{O}_{2}$ or $\mathrm{NH}_{3}$ considerably limits the minimum frequency under which the APTD occurs. Surprisingly, even if $\mathrm{N}_{2} \mathrm{O}$ is a more efficient quencher of $\mathrm{N}_{2}\left(\mathrm{~A}^{3} \Sigma_{\mathrm{u}}^{+}\right)$than $\mathrm{O}_{2}$, it can be added to $\mathrm{N}_{2}$ with no destabilisation of the discharge [88]. A possible explanation is the role of electrons attachment and detachment which have not been really considered up to now because of the low density of electrons in an APTD [44]. However, there is a possibility of attachment enhancement because the electrons which are continuously created (through one of the previously considered mechanisms) accumulate when the electric field is very low. Thus, according to the numerical modelling [89], the maximum density of electrons is about $7.10^{7} / \mathrm{cm}^{3}$ during the discharge and about $3.10^{8} / \mathrm{cm}^{3}$ when the electric field polarity is reversed. At this instant, the attachment probability is high (low electric field) and the detachment can occur later (when the electric field increases again). If the detachment occurs for an electric field lower than the one needed for the direct ionisation, this mechanism could create electrons under low field, allowing a slow ionisation. Work is still under progress to check this hypothesis and the possible contribution of electron attachment and detachment to the Townsend breakdown.

\section{GAS IONISATION SLOWDOWN}

The previous part explains why (i) a dielectric layer on each electrode is better to get a diffuse DBD, (ii) the excitation frequency influences the stability of an APGD (iii) the gas purity has to be high enough to get an APTD but not why a Penning mixture is necessary to get an APTD and how the electrical circuit can influence the discharge stability. The experimental parameters discussed up to now are related to the enhancement of $\gamma$ emission, those we will discuss now are related to the gas ionisation slowdown, condition to avoid a large electronic avalanche and thus a streamer and a microdischarge.

\subsection{Penning ionisation}

A Townsend breakdown is associated to a slower and lower ionisation of the gas than for a streamer breakdown. There is two solutions to slowdown the ionisation at the discharge ignition: (i) the enhancement of the two steps process ionisation (ii) the reduction of the voltage breakdown value.

Among two steps ionisation processes, Penning ionisation is the more common. In a Penning mixture of $\mathrm{M}$ with a small concentration of $\mathrm{A}$, the direct ionisation: $\mathrm{e}+\mathrm{M} \rightarrow \mathrm{M}^{+}+2 \mathrm{e}$ is in competition with the Penning ionisation: $\mathrm{e}+\mathrm{M} \rightarrow \mathrm{M}^{*}+\mathrm{e}$ followed by $\mathrm{M}^{*}+\mathrm{A} \rightarrow \mathrm{A}^{+}+\mathrm{e}+\mathrm{M}$. Penning ionisation pushes back the probability of making a large electronic avalanche and a streamer, because ionisation due to a two steps process is slower than a direct ionisation. Moreover, the energy needed to create the metastable state $\mathrm{M}^{*}$ is lower than that needed to directly create the ion. As example, in He the ionisation threshold is $24.6 \mathrm{eV}$ while that for $\mathrm{He}^{*}$ is $19,8 \mathrm{eV}$. Then, this process allows ionisation for a field lower than the breakdown voltage. This slow ionisation process promotes Townsend breakdown because the created ions have time to reach the cathode and then to induce secondary emission through bombardment before the ionisation level is high enough to localise the field. This is particularly true for $\mathrm{He}$ and $\mathrm{Ne}$, their metastables being able to ionise numerous gases, and in particular atmospheric gases, which are always present as residual gases in discharge vessels. It was also shown that in Ar, the adding of ketone [8] or $\mathrm{NH}_{3}$ helps to get APGD in conditions for which only localised discharges 
are obtained in pure $\operatorname{Ar}[69]$, and this under a voltage value down to 50\%.

The relative contribution of this mechanism depends on the variation of the ionisation rate with the electric field and on the variation of the electric field with time. The faster these variations, the lower the contribution of Penning ionisation will be. Therefore, this contribution is more important during breakdown when the field is low [89]. Nevertheless, experimental conditions can enhance Penning ionisation during the current increase. Indeed, as it can be seen on figure 2, the addition of a resistance in series with a He APGD decrease the electric field when the current increases resulting in an enhancement of the Penning ionisation (represented by $\mathrm{N}_{2}{ }^{+}$ions in figure 2) compared to the direct ionisation (represented by $\mathrm{He}^{+}$and $\mathrm{He}_{2}{ }^{+}$ions) reducing the ionisation speed and then the probability of making a large electronic avalanche.

Hence, Penning ionisation, because it is a two steps process, contributes to slowdown the gas bulk ionisation. Its contribution is significant under low field, when metastable excited states are preferentially created compared to ions. This is the case before and during breakdown, and during the discharge development when the electrical field is limited by the electrical circuit.

The contribution of Penning ionisation is clear. However other several steps ionisation which have to be pointed out could be involved.

\subsection{Power supply and electrodes configuration}

The power supply and the electrodes configuration (defined by the shape of the electrodes and the materials covering them) fix the current or the voltage applied to the gas after breakdown. For example, in a DBD, the solid dielectric imposes a voltage decrease proportional to the dielectric surface charge [2]. In an APTD, the gas voltage is more or less constant during the discharge and the current is thus fixed and equal to $\mathrm{C}_{\mathrm{ds}} \mathrm{dV}_{\mathrm{a}} / \mathrm{dt}$ where $\mathrm{C}_{\mathrm{ds}}$ is the equivalent capacitance of the solid dielectric and $\mathrm{V}_{\mathrm{a}}$ is the voltage applied to the electrodes [90]. In particular, the current maximum is independent of the gas characteristics. As shown in figure 6, if this current is too high, microdischarges can develop even after a Townsend breakdown. This has been also observed in Ar [76]. This is explained by the fact that the current fixed by the power supply being too high, the ionisation in the gas has to increase too much and leads to large size electronic avalanches. In the case where the ion density created by the first step of the discharge development is too low (typically $\leq 10^{10} / \mathrm{cm}^{3}$ ) to localise the field (like APTD), the space charge is negligible. The field is uniform and a large avalanche can always occur and induce the development of microdischarges.

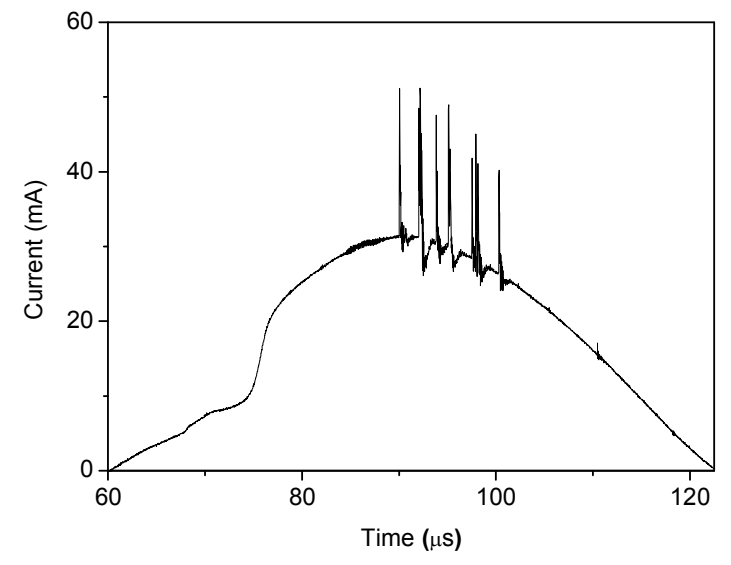

FIGURE 6. Microdischarges can develop after a Townsend breakdown. Current and gas voltage oscillogram of a $\mathrm{N}_{2}$ DBD mixing an APTD following a Townsend breakdown and microdischarges developing after the current maximum when the $\gamma$ coefficient is minimum and the current fixed by the power supply, the electrodes and the solid dielectrics.
As described in part 2, the adding of a choke coil [31] or of resistive material [29] increases the working domain of homogeneous DBD. It is interesting to push deeper the analyses of the role of these components. In a DBD, the dielectric is laid-out to avoid the transition from micro-discharge to arc. The coil or the resistive materials have to avoid the transition from the streamer to the micro-discharge or even from large avalanches to streamer by decreasing the gas voltage as soon as or before the ionisation level becomes high enough to localize the field. The time scale for arc transition is in the ms range, the time scale for streamer formation is in the ns range. Then, taking into account that a micro-discharge development is very fast and induces rather high current level, one can imagine that a component decreasing the gas voltage like the integral of the current will react too slowly (case of a capacitor), a resistance reacting proportionally to the current is better and one sensitive to the derivative is the best (case of an inductor). Then, the voltage decrease induced 
by these components will stop the discharge or enhanced low field ionization mechanism if there is. As shown figure 2 where the resistor in series with the discharge decreases the gas voltage and then increases the contribution of $\mathrm{N}_{2}^{+}$due to Penning ionization $\left(\mathrm{He}^{*}+\mathrm{N}_{2} \rightarrow \mathrm{N}_{2}^{+}+\mathrm{e}+\mathrm{He}\right)$

\section{CONCLUSION}

Homogeneous DBD are atmospheric pressure discharges free of microdischarge. For a given P.d product, they are obtained under low frequency alternative excitation when the experimental conditions allow a Townsend breakdown and when the discharge development is sufficiently slow. Townsend breakdown is a condition to get a stable and reproducible homogeneous discharge. It is obtained if there is enough seed electrons. According to all the results, these seed electrons result from a continuous emission of electrons from the cathode, due to a high $\gamma$ coefficient ensured by the presence of a dielectric on the cathode and due to a flux of energetic species impinging the surface previous to the breakdown. If a positive column is formed these species can be ions, if the life time of metastable is large enough it can be metastable. Negative ions may also play a role in the seed electrons enhancement in the case of electronegative gases. At each step, the amplification in the gas has to be limited to avoid the formation of a large electronic avalanche. This is obtained by the control of the current or voltage increase and by the enhancement of a slow ionisation process like Penning ionisation.

\section{REFERENCES}

[1] U. Kogelschatz, B. Eliasson, W. Egli, Pure Appl. Chem. 71, 1819 (1999)

[2] U. Kogelschatz, Plasma Chemistry and Plasma Processing 23, 1 (2003)

[3] A. Von Engel, R. Seeliger, M. Steenbeck, Z. Phys. 85, 144 (1933)

[4] R. Bartnikas, J. Appl. Phys. 401974 (1969)

[5] S. Kanazawa, M. Kogoma, T. Moriwaki, S. Okazaki, J. Phys. D: Appl. Phys. 21, 838 (1988)

[6] S. Okazaki, M. Kogoma, H. Uchimaya, in Proc. of the $3^{\text {rd }}$ Int. Symp. High Pressure Low Temperature Plasma Chemistry (Hakone III), 1991, 101

[7] N. Kanda, M. Kogoma, H. Jinno, H. Uchiyama, S. Okazaki, in Proc. of the $10^{\text {th }}$ Int. Symp. On Plasma Chemistry, 1991, 3, 2

[8] S. Okazaki, M. Kogoma, M. Uehara, Y. Kimura, J. Phys. D: Appl. Phys. 26, pp. 889-892 (1993)

[9] R. Messaoudi, F. Massines, A. Younsi, B. Despax and C. Mayoux, in Proc. of the 10 ${ }^{\text {th }}$ Int. Conf. Gas Disch. And App., 1992, Swansea, pp. 318-321

[10] F. Massines, C. Mayoux, R. Messaoudi, A. Rabehi, P. Ségur, in Proc. of the $10^{\text {th }}$ Int. Conf. Gas Disch. And App., 1992, Swansea, pp. 730-733

[11] F. Massines, A. Rabehi, Ph. Decomps, R. Ben Gadri, P. Ségur, Ch. Mayoux, J. App. Phys. 38, p. 2950 (1998)

[12] I. Enache, N. Naudé, J.P. Cambronne, N. Gherardi, F. Massines, Eur. Phys. J. Appl. Phys. 33, 1, pp. 15-21 (2006)

[13] N. Gherardi, F. Massines, IEEE Trans. on Plasma Sci.29, 3, pp. 536-44 (2001)

[14] F. Massines, P. Ségur, N. Gherardi, C. Khamphan, A. Ricard, Surface and Coatings Technology 174-175, pp. 8-14 (2003)

[15] N. Naudé, J.P. Cambronne, N. Gherardi, F. Massines, J. Phys. D: Appl. Phys. 38, 4, pp. 530-538 (2005)

[16] F. Massines, G. Gouda, J. Phys. D: Appl. Phys. 31, 24, pp. 3411-3420 (1998)

[17] F. Massines, G. Gouda, N. Gherardi, M. Duran and E. Croquesel. Plasmas and Polymers, 6, pp. 35-49 (2001)

[18] N. Gherardi, S. Martin, F. Massines, J. Phys. D: Appl. Phys. 33, 19, pp. L104-8 (2000)

[19] S. Martin, F. Massines, N. Gherardi, C. Jimenez, Surface and Coatings Technology 177-178, pp. 693-698 (2004)

[20] F. Massines, N. Gherardi, A. Fornelli, S. Martin, Surface and Coatings Technology 200, 5-6, pp. 1855-1861 (2005)

[21] P. Tsai, L. Wadsworth, J. R. Roth, Textile Research Journal 67, 5, pp. 359-369 (1997)

[22] J. R. Roth, Z. Chen, P. P.-Y. Tsai, Acta Metallurgica Sinica 14, 6, pp. 391-407 (2001)

[23] J.R. Roth, Physics of Plasmas 12, 5-2 (2005)

[24] J. R. Roth, J. Rahel, X. Dai, D. M. Sherman, J. Phys. D: Appl. Phys. 38, 4, pp. 555-567 (2005)

[25] K. Kelly-Wintenberg, T. C. Montie, T. C. Brickman, J. R. Roth, A. K. Carr, K. Sorge, L. C. Wadsworth, P.

P.-Y Tsai, Journal of Industrial Microbiology \& Biotechnology 2, pp. 69-74 (1998)

[26] T. C. Montie, K. Kelly-Wintenberg, J. R. Roth, IEEE Trans. Plasma Sci. 28, 1, pp. $41-50$ (2000) 
[27] J. R. Roth, D. M. Sherman, S. P. Wilkinson, AIAA Journal 38, 7, pp 1166-1172 (2000).

[28] J. R. Roth, Physics of Plasmas 10, 5 (2003)

[29] M. Laroussi, I. Alexeff, J. P. Richardson, F. Dyer, IEEE Trans. Plasma Sci. 30, 1, (2002)

[30] T. Terajima, H. Koinuma, Applied Surface Science 223, pp. 259-263 (2004)

[31] E. Aldea, MCM Van-De-Sanden, P. Peeters; H. De-Vries, Surface-and-Coatings-Technology. 200, pp. 4650 (2005)

[32] D. Trunec, A. Brablec, F. Stastny, Contributions-to-Plasma-Physics 38, 3, pp. 435-445 (1998)

[33] F. Tochikubo, T. Chiba, T. Watanabe, Jpn. J. Appl. Phys. Part 1, 38, 9A, pp. 5244-5250 (1999)

[34] S.F. Miralai, E. Monette, R. Bartnikas, G. Czeremuszkin, M. Latreche, M.R. Wertheimer, Plasmas and Polymers 5, 2 , pp. 63-77 (2000)

[35] T. Nozaki, Y. Miyazaki, Y. Unno, K. Okazaki, J. Phys. D: Appl. Phys. 34, pp. 3383-3390 (2001)

[36] Yu. B. Golubovskii, V. A. Maiorov, J. Behnke and J. F. Behnke, J. Phys. D: Appl. Phys. 35, pp. 751-761 (2002)

[37] M. Madani, A. Bogaerts, R. Gijbels, D. Vangeneugden, in Proc. of the $8^{\text {th }}$ Int. Symp. High Pressure Low Temperature Plasma Chemistry (Hakone VIII), Puhajarve, Estonia, 2002, pp. 130-133

[38] I. Radu, R. Bartnikas, M.R. Wertheimer, J. Phys. D: Appl. Phys. 36, 11, pp. 1284-91 (2003)

[39] Yu. B. Golubovskii, V. A. Maiorov, J. Behnke, J. F. Behnke, J. Phys. D: Appl. Phys. 36 (2003)

[40] T. Callebaut, I. Kochetov, Yu Akishev, A. Napartovich,C. Leys, Plasma Sources Sci. Technol. 13, pp. 245250 (2004)

[41] L. Mangolini, C. Anderson, J. Heberlein, U. Kortshagen, J. Phys. D: Appl. Phys. 37, 7, pp. 1021-1030 (2004)

[42] Peng-Zhang, U. Kortshagen, IEEE Trans. on Plasma Sci. 33, 2, pp. 318-319 (2005)

[43] J.J. Shi, D.W. Liu, M.J. Kong, Appl. Phys. Lett. 89, 081502 (2006)

[44] R. Brandenburg, V. A. Maiorov, Yu B. Golubovskii, H-E Wagner, J. Behnke, J. F. Behnke, J. Phys. D: Appl. Phys. 38, pp. 2187-2197 (2005)

[45] A. Bogaerts, K. De-Bleecker, V. Georgieva, I. Kolev, M. Madani, E. Neyts, Plasma-Processes-andPolymers 3(2), pp. 110-19 (2006)

[46] R. Bartnikas, I. Radu, M.R. Wertheimer, IEEE Trans. on Plasma Sci. 35, 5, pp. 1437-47 (2007)

[47] T. Yokoyama, M. Kogoma, S. Kanazawa, T. Moriwaki, S. Okazaki, J. Phys. D: Appl. Phys. 23, 3, pp. 374377 (1990)

[48] Y. Sawada, S. Ogawa, M. Kogoma, J. Phys. D: Appl. Phys. 28, 1661-1669 (1995)

[49] K. Schmidt-Szalowski, W. Fabianowski, Z. Rzanek-Boroch, J. Sentek, J. Chem. Vap. Deposition 6, p. 183195 (1998)

[50] R. Prat, Y.J. Koh, Y. Babukutty, M. Kogoma, S. Okazaki, M. Kodama, Polymer 41, pp. 7355-7360 (2000)

[51] O. Goossens, E. Dekempeneer, D. Vangeneugden, R. Van de Leest, C. Leys, Surface and Coatings Technology 142-144, pp. 474-481 (2001)

[52] A. Sonnenfeld, T. M. Tun, L. Zajıckova, K. V. Kozlov, H.-E. Wagner, J. F. Behnke, R. Hippler, Plasmas and Polymers 6, 4 (2001)

[53] H.-E. Wagner, R. Brandenburg, K. V. Kozlov, A. Sonnenfeld, P. Michel, J.F. Behnke, Vaccuum 71, pp. 417-436 (2003)

[54] R. Foest, F. Adler, F. Sigeneger, M. Schmidt, Surface and Coatings Technology 163-164, pp. 323-330 (2003)

[55] L.J. Ward, W.C.E. Schofield, J.P.S. Badyal, A.J. Goodwin, P.J. Merlin, Chem. Mater. 15, pp. 1466-1469 (2003)

[56] D. Trunec, Z. Navratil, P. Stahel, L. Zajickova, V. Bursikova, J. Cech, J. Phys. D: Appl. Phys. 37, pp. $2112-$ $2120(2004)$

[57] S. E. Alexandrov, M. L. Hitchman, Chem. Vap. Deposition 11, pp. 457-468 (2005)

[58] F. Fanelli, F. Fracassi, R. d’Agostino, Plasma Process. Polym. 2, pp. 688-694 (2005)

[59] E. Njatawidjaja, M, Kodoma, K. Matsuzaki, K. Yasuda, T. Matsuda, Plasma Processes and Polymers 3, pp. 338-341 (2006)

[60] M. Laroussi, IEEE Trans. on Plasma Sci. 24, 3, pp. 1188-91 (1996)

[61] T. Akitsu, H. Ohkawa, M. Tsuji, H. Kimura, M. Kogoma, Surface-and-Coatings-Technology 193, 1-3, pp. 29-34 (2005)

[62] M.K. Boudam, M. Moisan, B. Saoudi, C. Popovici, N. Gherardi, F. Massines, J. Phys. D: Appl. Phys. 39, 16, pp. 3494-3507 (2006)

[63] M.K. Boudam, M. Moisan, B. Saoudi, C. Popovici, N. Gherardi, F. Massines, J. Phys. D: Appl. Phys. 39, 16 pp. 3494-3507 (2006)

[64] H. Ohkawa, T. Akitsu, M. Tsuji, H. Kimura, M. Kogoma, K. Fukushima, Surf. And Coat. Technol. 200, pp. 5829-5835 (2006)

[65] G. Fridman, G. Friedman, A. Gutsol, A. B. Shekhter, V. N. Vasilets, A. Fridman, Plasma Processes and 
Polymers, doi: 10.1002/ppap.200700154 (2008)

[66] J. Pons, E. Moreau, G. Touchard, J. Phys. D: Appl. Phys. 38, 19 pp. 3635-42 (2005)

[67] A. Seraudie, E. Aubert, N. Naudé, J-P Cambronne, in Proc. of the $3^{\text {rd }}$ AIAA Flow Control Conference, june 5-8 2006, San Francisco

[68] J.P. Boeuf, Y. Lagmich, T. Unfer, T. Callegari, L.C. Pitchford, J. Phys.D:Appl. Phys. 40, 3, pp. $652-662$ (2007)

[69] N. Gherardi, E. Croquesel, F. Massines, in Proc. of the $16^{\text {th }}$ International Symposium on Plasma Chemistry, (ISPC 16), June 22- 27 2003, Taormina, Italy

[70] F. Massines, N. Gherardi, N. Naudé, P. Ségur, Plasma Phys. Control. Fusion 47, pp. B577-B588 (2005)

[71] N. Naudé, S. Okazaki, N. Gherardi and F. Massines, in Proc. of the $18^{\text {th }}$ International Symposium on Plasma Chemistry (ISPC 18), august 26-31 2007, Kyoto, Japan

[72] Yu. P. Raizer, in Gas Discharge Physics, edited by Springer-Verlag, Berlin (1991)

[73] J.Tepper, M. Lindmayer, J. Salge, in Proc. Of Hakone VI, 31 august - 02 september 1998, Cork, Ireland

[74] J. Tepper, P. Li, M. Lindmayer, in Proc. of the XIV Int. Conf. on Gas Discharges and their Applications, Liverpool, September 1-6 2002, pp.1-4

[75] X. Wang, H. Luo, Z. Liang, T. Mao, R. Ma, Plasma Sources Sci. Technol. 15, pp 845-848 (2006)

[76] N. Naudé, F. Massines, IEEE Trans.Plasma Sci., doi 10.1109/TPS.2008.923899 (2008)

[77] P. Decomps,tF. Massines, Ch. Mayoux, in Proc. of the $23^{\text {rd }}$ Int. Conf. on Phenomena in Ionized Gases (XXIII ICPIG), 17-22 July, 1997, Toulouse, France

[78] N. Naudé, N. Gherardi, ET. Es-Sebbar, J.P. Cambronne, F. Massines, in Proc. Of the $9^{\text {th }}$ International Symposium on High Pressure Low Temperature Plasma Chemistry (Hakone IX), August 23-26, 2004, Padova Italy

[79] Jichul Shin, Laxminarayan L Raja, J. Phys. D: Appl. Phys. 40, pp. 3145-3154 (2007)

[80] Kai Wu, L.A. Dissado, IEEE Trans. on Dielectrics and Electrical Insulation 12(4), pp. 655-668 (2005)

[81] R. Ben Gadri, PhD Thesis, University of Toulouse (1997)

[82] G Dilecce, P F Ambrico, S De Benedictis, Plasma Sources Sci. Technol. 16, pp. 511-522 (2007)

[83] N. Gherardi, G. Gouda, E. Gat, A. Ricard, F. Massines, Plasma Sources Sci. Technol. 9, pp. 340-346 (2000)

[84] Y.B. Golubovskii, V.A. Maiorov, J. Behnke, J. F. Behnke, J. Phys. D: Appl. Phys. 35, pp. 751-61 (2002)

[85] C. Khamphan, P. Ségur, F. Massines, M.C. Bordage, N. Gherardi and Y.Cesses, in Proc. of the $16^{\text {th }}$ International Symposium on Plasma Chemistry, Taormina, Italy, 2003

[86] P.F. Little, Secondary effects in: Electron Emission gas discharges I - volume XXI, Encyclopedia of physics, edited by S. Flugge (1956)

[87] D.A. Bosan, T.V. Jovanovic, D. M. Krmpotic, J. Phys.D:Appl. Phys 30, pp. 3096-3098 (1997)

[88] N. Gherardi, N. Naudé, Et. Es-Sebbar, I. Enache, H. Caquineau, F. Massines, in Proc. of the 10 ${ }^{\text {th }}$ Int. Symp. on High Pressure Low Temp. Plasma Chemistry (Hakone X), september 4-8, 2006, Saga, Japan, pp. 21-24

[89] P. Ségur, F. Massines, in Proc. of the $12^{\text {th }}$ Int. Conf. on Gas Discharge and their Appl., september 3-8 (2000)

[90] E. Croquesel, N. Gherardi, S. Martin, F. Massines, in Proc. of the $8^{\text {th }}$ Int. Symp. on High Pressure Low Temp. Plasma Chemistry (Hakone VII), September 10-13, 2000, Greifswald, Germany 